\title{
Oestrogen has no short-term effect on intestinal strontium absorption in healthy postmenopausal women
}

\author{
Marieke ten Bolscher*, Gerdien W. de Valk-de Roo*, \\ Rob Barto†, Wim J. F. van der Vijgh† and \\ J. Coen Netelenbos* \\ * Department of Endocrinology and + Clinical Research \\ Laboratory of Internal Medicine, University Hospital Vrije \\ Universiteit, Amsterdam, The Netherlands
}

(Received 19 May 1998; returned for revision 17 July 1998; finally revised 31 August 1998; accepted 30 September 1998)

\section{Summary}

OBJECTIVE Impaired intestinal calcium absorption in postmenopausal women is often indirectly linked to decreased serum $1,25(\mathrm{OH})_{2} \mathrm{D}$ or to intestinal resistance to its action rather than directly to low circulating oestrogen levels following the menopause. The purpose of this clinical study was to investigate the short-term effect of oral $17 \beta$-oestradiol on intestinal calcium absorption, with strontium as a marker.

DESIGN AND PATIENTS Twenty-five healthy postmenopausal women participated in this randomised double blind placebo controlled clinical trial. Twelve women received oestradiol therapy $(2 \mathrm{mg} / \mathrm{day})$ and thirteen placebo for 2 months. Fractional strontium absorption $\left(\mathrm{Fc}_{240}\right)$ was assessed at baseline and after 2 months of oestradiol/placebo therapy.

RESULTS Intestinal strontium absorption $\left(\mathrm{Fc}_{240}\right)$ was unchanged after treatment with $17 \beta$-oestradiol (10.1 \pm 5.0 vs. $10.2 \pm 3.8(\%))$. Serum total calcitriol $\left(1,25(\mathrm{OH})_{2}\right.$ D) was unchanged after treatment with placebo $(88 \pm$ 22 vs. $79 \pm 21$ (pmol/l)) but increased after treatment with oestradiol ( $88 \pm 30$ vs. $116 \pm 33(\mathrm{pmol} / \mathrm{l}) ; P<0.005)$. Serum vitamin $D$ binding protein (DBP) increased after oestradiol but not after placebo treatment. The free serum $1,25(\mathrm{OH})_{2} \mathrm{D}$ index was calculated. This index did not change after oestrogen therapy (1.6 \pm 0.5 vs. $1.8 \pm 0.5)$.

CONCLUSION In healthy postmenopausal women, short-term suppletion with exogenous oral oestrogen

Correspondence: Marieke ten Bolscher, Department of Endocrinology, University Hospital Vrije Universiteit, PO Box 7057, 1007 MB Amsterdam, The Netherlands. Fax: +31-20-4443844;

E-mail: M.tenBolscher@azvu.nl did not influence intestinal calcium absorption as measured by the strontium absorption test.

It is well known that ovarian hormone deficiency is a major risk factor for osteoporosis in postmenopausal women (Prince, 1994). Postmenopausal osteoporosis is often associated with intestinal malabsorption of calcium (Gallagher et al., 1979). Impaired calcium absorption is believed to aggravate a negative calcium balance and contribute to bone loss in postmenopausal women (Gallagher et al., 1980; Heaney et al., 1978).

Gastrointestinal absorption of calcium is a sum of two processes: a saturable (active) and a non-saturable (passive) one (Blanchard \& Aeschlimann, 1989). Passive absorption is a function of ingested calcium load and is neither saturable nor subject to regulation in human (Barger-Lux \& Heaney, 1995). The active component of intestinal calcium absorption appears to be under relatively rigid hormonal control in which $1,25(\mathrm{OH})_{2} \mathrm{D}$ plays a dominant role.

There is a considerable uncertainty about the underlying cause of calcium malabsorption in postmenopausal women. It has often been attributed to decreased serum $1,25(\mathrm{OH})_{2}$ vitamin D levels (Gallagher, 1990) and to intestinal resistance to its action (Gennari et al., 1990), which could lead to a reduction of active intestinal calcium absorption (Francis et al., 1984; Morris et al., 1991). Recent in vitro and in vivo data showed that rat intestinal mucosa contained oestrogen receptor immunoactivity and responded to estradiol (Arjmandi et al., 1993, 1994). These findings suggest that oestrogen may have a physiological role in the regulation of intestinal calcium absorption and that its deficiency in postmenopausal osteoporosis may directly result in intestinal calcium malabsorption. Therefore, the purpose of our study was to examine the effect of oestrogen on intestinal calcium absorption in healthy postmenopausal women.

Three methods are available for the measurement of intestinal calcium absorption in human: a full calcium balance which requires a stay of at least 2 weeks in a metabolic unit and is impractical for routine use; a double isotope procedure, with two either stable or radioactive calcium isotopes, which has a number of technical difficulties and implies a delay of several weeks before yielding a result; and a single isotope procedure, which is the simplest, cheapest and quickest method. For clinical use a simple, easy to perform intestinal absorption test with minor discomfort for the patient is preferred and thus 
suitable for large-scale application and frequently repeated tests within one person.

Nonradioactive stable strontium has been used as a tracer for calcium, to measure intestinal calcium absorption. A close correlation between the absorption of strontium and ${ }^{45} \mathrm{Ca}$ has been reported in normal subjects and in patients with various disorders of calcium metabolism (Reid et al., 1986). A simple clinical test for estimating intestinal calcium absorption using stable strontium was elaborated in our group (Sips et al., 1996). Using this test in healthy male volunteers, we found that the true bioavailability of strontium correlated best with the fractional absorption of strontium at 240 minutes $\left(\mathrm{Fc}_{240}\right)$ after oral intake of strontium.

Fractional absorption of strontium $\left(\mathrm{Fc}_{240}\right)$ is based on extracellular fluid volume. Usually, $15 \%$ of the body weight is used as an estimation of the extracellular volume (ECV) to calculate fractional absorption (Civitelli et al., 1988; Need et al., 1987; Gennari et al., 1997). However, hormonal intervention may change the ECV and can thus result in an apparent change in intestinal absorption. Therefore, we assessed the ECV at the basal level and after oestrogen intervention and used the ECV, instead of $15 \%$ of body weight, for calculating the $\mathrm{Fc}_{240}$ of strontium. This gives us the opportunity to correct for a changing volume of ECV when necessary.

This adapted test was used to investigate the effect of oestrogen on intestinal strontium absorption in healthy postmenopausal women.

\section{Materials and methods}

\section{Study population}

Twenty-six healthy postmenopausal women participated in the study after written informed consent. Fifteen women endured hysterectomy. In the other women menopause was presumed to be present if the menstrual cycle had stopped for more than a year. Menopause was confirmed biochemically by low plasma oestradiol levels ( $<95 \mathrm{pmol} / \mathrm{l})$ and by follicle-stimulating hormone (FSH) plasma levels exceeding $30 \mathrm{IU} / \mathrm{l}$. Major exclusion criteria were: known or suspected oestrogen-dependent carcinoma, known thromboembolic disease, diabetes mellitus, a history of excessive alcohol ingestion, changes of body weight $>4 \mathrm{~kg}$ during the previous 4 weeks, intake of corticosteroids during the previous 6 months, intake of female sex hormones during the previous 3 months or any medication influencing calcium and bone homeostasis. Women with a serum creatinine $>100 \mu \mathrm{mol} / \mathrm{l}$, ALAT (liver enzyme) $>100 \mathrm{U} / \mathrm{l}$, alkaline phosphatase $>300 \mathrm{U} / \mathrm{l}$ were also excluded. One participant dropped out of the study because of a hospital admission for varicose vein treatment. Data in this study are therefore based on 25 women (mean age 52.9, range 48 to 57 years) randomly assigned to either $17 \beta$-oestradiol or placebo.
All subjects gave informed consent to participate in the study, which was performed in our outpatient clinic of the University Hospital Vrije Universiteit, Amsterdam. The study was approved by the ethics committee of our hospital. All procedures followed were in accordance with the Declaration of Helsinki.

\section{Study design}

All subjects came to the hospital after overnight fasting. Blood samples were obtained for the determination of plasma strontium, bromide, calcium, albumin, phosphate, serum $1,25(\mathrm{OH})_{2} \mathrm{D}$ and DBP. Because of the possibility that oestrogen could change the extracellular fluid volume (ECV), necessary for the calculation of the fractional absorption of strontium $\left(\mathrm{Fc}_{240}\right)$, the ECV was assessed by means of an intravenous injection (in 10 minutes) of sodium bromide $(1 \mathrm{ml} / \mathrm{kg}$ of an aqueous $5 \%$ sodium bromide solution, which is equivalent to $38.8 \mathrm{mg} \mathrm{Br} / \mathrm{kg}$ ). After administration of sodium bromide subjects received a $200 \mathrm{ml}$ test solution, which contained $5 \cdot 0$ mmol $\mathrm{SrCl}_{2}$ in the middle of a standardized meal, which consisted of $150 \mathrm{~g}$ Fortipudding with vanilla flavour (Nutricia, Zoetermeer, The Netherlands). Both the pudding and the test solution were consumed in approximately 3 to 4 minutes. The pudding was a semi-solid ready to eat standardized nutritional supplement. Four hours after ingestion of strontium a blood sample was withdrawn for the determination of plasma bromide and strontium. Blood samples were centrifuged at $1500 \mathrm{~g}$ for 10 min. Subsequently, plasma was separated and stored at $-20^{\circ} \mathrm{C}$ until analysis. All plasma samples were analysed for strontium by graphite furnace atomic absorption spectrophotometry (Barto et al., 1995) and for bromide by ion-exchange chromatography (Miller et al., 1989, with modifications). Solutions of $\mathrm{NaBr}$ and $\mathrm{SrCl}_{2} \cdot 6 \mathrm{H}_{2} \mathrm{O}$ (p.a., Merck, Amsterdam, The Netherlands) were prepared by the Pharmacy Department of the University Hospital Vrije Universiteit.

After this test, participants were randomised to either treatment with $17 \beta$-oestradiol, $2 \mathrm{mg}$ orally a day (Zumenon, Solvay Pharma, Weesp, The Netherlands) or placebo for 2 months. They had to take this medication in the morning before breakfast. The strontium absorption test was repeated at the end of the study i.e. 2 months after the first test.

\section{Methods}

Serum FSH was measured by a luminescence immunometric assay (Amerlite, Amersham, UK). Intra- and inter-assay coefficients of variation were $5 \%$ and $7 \%$, respectively. Serum oestradiol was measured by a double radioimmunoassay (RIA) (Sorin Biomedica, Saluggia, Italy). Intra- and inter-assay coefficients of variations were $4.5 \%$ and $10.5 \%$, respectively. 
Table 1 Characteristics of the participating women. Values are expressed as mean $\pm \mathrm{SD}$.

\begin{tabular}{lcc}
\hline & & \\
Parameter & Placebo $(n=13)$ & Oestrogen $(n=12)$ \\
\hline Age (years) & $52 \cdot 9 \pm 2 \cdot 8$ & $53 \cdot 4 \pm 3 \cdot 4$ \\
Weight $(\mathrm{kg})$ & $70 \cdot 9 \pm 11 \cdot 1$ & $75 \cdot 2 \pm 12 \cdot 5$ \\
Height $(\mathrm{m})$ & $1 \cdot 67 \pm 0 \cdot 04$ & $1 \cdot 65 \pm 0 \cdot 09$ \\
ECV $(\mathrm{l})$ & $16 \cdot 7 \pm 3 \cdot 5$ & $16 \cdot 0 \pm 1 \cdot 9$ \\
FSH $(\mathrm{U} / \mathrm{l})$ & $59 \cdot 8 \pm 21 \cdot 6$ & $55 \cdot 2 \pm 20 \cdot 3$ \\
Oestradiol $(\mathrm{pmol} / \mathrm{l})$ & $26 \cdot 1 \pm 8 \cdot 6$ & $39 \cdot 9 \pm 24 \cdot 3$ \\
Albumin $(\mathrm{g} / \mathrm{l})$ & $41 \pm 2$ & $41 \pm 2$ \\
Total protein $(\mathrm{g} / \mathrm{l})$ & $70 \pm 4$ & $69 \pm 4$ \\
Calcium $(\mathrm{mmol} / \mathrm{l})$ & $2 \cdot 32 \pm 0 \cdot 06$ & $2 \cdot 30 \pm 0 \cdot 07$ \\
Phosphate $(\mathrm{mmol} / \mathrm{l})$ & $0 \cdot 94 \pm 0 \cdot 14$ & $0 \cdot 97 \pm 0 \cdot 17$ \\
$25(\mathrm{OH}) \mathrm{D}_{3}(\mathrm{nmol} / \mathrm{l})$ & $71 \pm 19$ & $61 \pm 21$ \\
$1,25(\mathrm{OH})_{2} \mathrm{D}(\mathrm{pmol} / \mathrm{l})$ & $88 \pm 22$ & $88 \pm 30$ \\
DBP $(\mathrm{mg} / \mathrm{l})$ & $325 \pm 54$ & $310 \pm 45$ \\
Free $1,25(\mathrm{OH})_{2} \mathrm{D}$ index & $1 \cdot 6 \pm 0 \cdot 5$ & $1 \cdot 6 \pm 0 \cdot 5$ \\
& & \\
\hline
\end{tabular}

None of the differences between groups is significant.

Serum $1,25(\mathrm{OH})_{2} \mathrm{D}$ was measured by radioimmunoassay after immune-extraction (IDS, Tyne and Wear, UK). Intra- and interassay coefficients of variation were $6.3 \%$ and $9.7 \%$, respectively. Serum vitamin D-binding protein (DBP) was determined by Bouillon et al. (1977), and the free serum index of $1,25(\mathrm{OH})_{2} \mathrm{D}$ was calculated as the molar ratio of $1,25(\mathrm{OH})_{2} \mathrm{D}$ concentration to DBP concentration (Bouillon et al., 1981).

The ECV was calculated from the plasma $\mathrm{Br}^{-}$concentration, after an intravenous injection of the sodium bromide solution (38.8 $\mathrm{mg} \mathrm{Br}^{-} / \mathrm{kg}$ ), according to the following formula (Miller et al., 1989).

$\mathrm{ECV}(\mathrm{L})=\frac{\mathrm{Br}^{-} \text {dose }(\mathrm{mmol})}{\left[\mathrm{Br}^{-}\right]_{\mathrm{t}=240 \min }-\left[\mathrm{Br}^{-}\right]_{\mathrm{t}=0 \mathrm{~min}}(\mathrm{mmol} / \mathrm{l})} \times 0.90 \times 0.95$

in which 0.90 is the correction factor for the distribution of $\mathrm{Br}^{-}$ in the non-extracellular sites (principally red blood cells) and 0.95 is the correction factor for the Donnan equilibrium. Intestinal strontium absorption was calculated according to the following formula (Sips et al., 1996):

$$
\mathrm{Fc}_{240}(\%)=\frac{\left[\mathrm{C}_{\mathrm{t}}-\mathrm{C}_{0}\right] \times \mathrm{V}}{\mathrm{D}} \times 100
$$

in which $C_{t}=$ plasma concentration at $240 \mathrm{~min}, C_{0}=$ plasma concentration at $0 \mathrm{~min}, \mathrm{~V}$ is the central volume of distribution represented by the ECV and measured by means of sodium bromide, $\mathrm{D}=$ dose of strontium $=5.0 \mathrm{mmol}$. The short $(1$ month)- and long-term (6 months) precisions (standard error of reproducibility, $\mathrm{SE}_{\mathrm{R}}$ ) assessed in our laboratory in 8 healthy male volunteers and 12 healthy postmenopausal women were $1.85 \%$ and $1.63 \%$, with intra-assay coefficients of variation (CV) of $19.6 \%$ and $28.6 \%$, respectively.

\section{Statistical analysis}

Values are expressed as mean (SD). The difference between two months of therapy and basal values was calculated for all biochemical parameters and expressed as delta $(\Delta)$. The difference between the placebo and oestrogen treated group was tested for a significant difference between the delta values by a Student $t$-test for independent samples. Statistical difference was defined as $P<0.05$ (two tailed). All analyses were performed using the Statistical Package for the Social Sciences (SPSS 7.0 for windows).

\section{Results}

Baseline characteristics of the participating women are presented in Table 1. There were no significant differences in the basal values between the placebo and the treatment groups. No adverse effects of the intervention were reported.

Table 2 Effect of oestrogen treatment on metabolic parameters. Significant differences from placebo values by Student's t-test for independent samples $(* P<0.005, * * P<0 \cdot 001)$. Values are expressed as mean \pm SD.

\begin{tabular}{|c|c|c|c|c|}
\hline & \multicolumn{2}{|c|}{ Basal } & \multicolumn{2}{|c|}{ Change after treatment $(\Delta)$} \\
\hline & Placebo $(n=13)$ & Oestrogen $(n=12)$ & Placebo $(n=13)$ & Oestrogen $(n=12)$ \\
\hline ECV (1) & $16 \cdot 7 \pm 3 \cdot 5$ & $16 \cdot 0 \pm 1 \cdot 9$ & $+0.47 \pm 1.4$ & $+0 \cdot 88 \pm 0.55$ \\
\hline $\mathrm{Fc}_{240}(\%)$ & $9 \cdot 2 \pm 3 \cdot 0$ & $10 \cdot 1 \pm 5 \cdot 0$ & $+0.98 \pm 2.8$ & $+0 \cdot 1 \pm 2 \cdot 1$ \\
\hline Calcium (mmol/l) & $2 \cdot 32 \pm 0.06$ & $2 \cdot 30 \pm 0.07$ & $+0.0009 \pm 0.06$ & $+0.003 \pm 0.03$ \\
\hline Phosphate (mmol/l) & $0 \cdot 94 \pm 0 \cdot 14$ & $0.97 \pm 0 \cdot 17$ & $-0 \cdot 002 \pm 0 \cdot 4$ & $-0.03 \pm 0.40$ \\
\hline $25(\mathrm{OH}) \mathrm{D}_{3}(\mathrm{nmol} / \mathrm{l})$ & $71 \pm 19$ & $61 \pm 21$ & $-8 \pm 12$ & $+0 \cdot 1 \pm 9$ \\
\hline $1,25(\mathrm{OH})_{2} \mathrm{D}(\mathrm{pmol} / \mathrm{l})$ & $88 \pm 22$ & $88 \pm 30 \cdot 0$ & $-9 \pm 19$ & $+32 \pm 33 *$ \\
\hline DBP (mg/l) & $325 \pm 54$ & $310 \pm 45$ & $-15 \pm 44$ & $+55 \pm 37 * *$ \\
\hline Free $1,25(\mathrm{OH})_{2} \mathrm{D}$ index & $1 \cdot 6 \pm 0 \cdot 5$ & $1 \cdot 6 \pm 0 \cdot 5$ & $-0 \cdot 1 \pm 0 \cdot 4$ & $+0 \cdot 3 \pm 0 \cdot 5$ \\
\hline
\end{tabular}



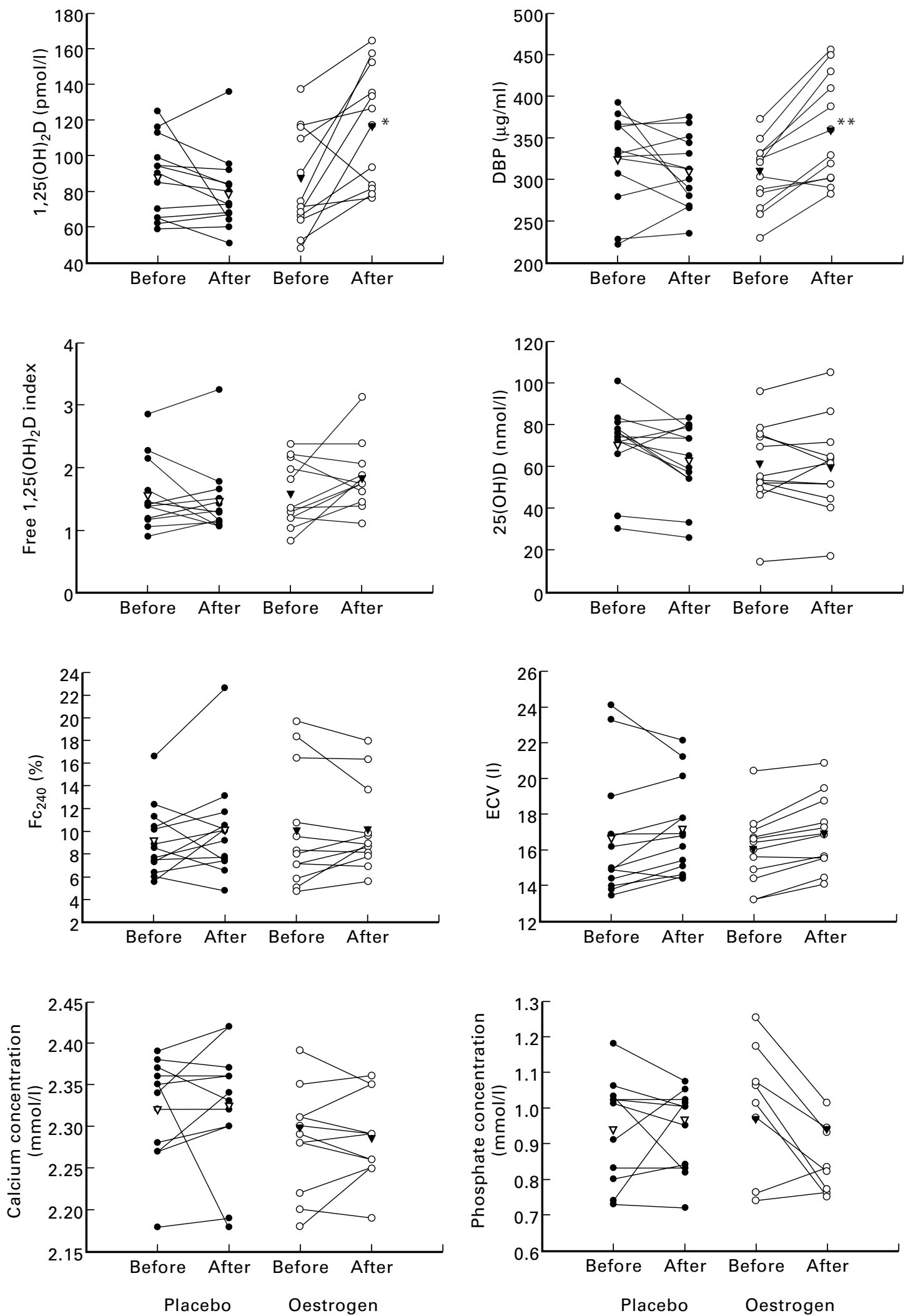

Fig. 1 The effect of 2 months of oestrogen supplementation on intestinal strontium absorption $\left(\mathrm{Fc}_{240}\right)$, ECV and biochemical parameters in healthy postmenopausal women. $\nabla,(\mathbf{\nabla})$ : mean of the group. $* P<0 \cdot 005, * * P<0 \cdot 001$. 
Oestradiol therapy did not change serum calcium, phosphate, and $25(\mathrm{OH}) \mathrm{D}_{3}$ (Table 2). Furthermore, oestrogen did not show a significant change in extracellular fluid volume (Fig. 1). A 2month treatment with oestrogen increased serum levels of total $1,25(\mathrm{OH})_{2} \mathrm{D}$ and vitamin D-binding protein significantly, expressed as $\Delta$ values, compared to the placebo-treated group $(P<0.005$ and $P<0.001$, respectively). However, the calculated free $1,25(\mathrm{OH})_{2} \mathrm{D}$ index did not show a significant change. Intestinal calcium absorption, as measured by the strontium absorption test $\left(\mathrm{Fc}_{240}\right)$, did not change after treatment with oestrogen compared to the placebo-treated group (Fig. 1).

\section{Discussion}

In this short-term randomised double-blind placebo controlled clinical study we have shown that treatment with $17 \beta$ oestradiol in healthy postmenopausal women did not affect intestinal calcium absorption as measured by the strontium absorption test $\left(\mathrm{Fc}_{240}\right.$ of strontium). The existing data on the effect of oestrogen on intestinal calcium absorption are conflicting. Gallagher et al. (1980) and Civitelli et al. (1988) described a significant positive effect of oestrogen treatment on intestinal calcium absorption in postmenopausal osteoporotic women, using dual tracer and single tracer absorption tests, respectively. Other reports (Balhorn et al., 1997; Heaney et al., 1978; Selby et al., 1985) demonstrated that oestrogen suppletion did not significantly increase intestinal calcium absorption. Balhorn et al. (1997) and Selby et al. (1985) used a single tracer absorption test, whereas Heaney et al. (1978) measured intestinal calcium absorption by a dual tracer test under balance conditions. Gallagher et al. (1980) and Civitelli et al. (1988) showed that the efficiency of intestinal calcium absorption in postmenopausal osteoporotic women improved in parallel with an oestrogen-induced rise in serum $1,25(\mathrm{OH})_{2} \mathrm{D}$ level, suggesting that biologically active $1,25(\mathrm{OH})_{2} \mathrm{D}$ had indeed increased. They concluded therefore, that oestrogen treatment increases intestinal calcium absorption in postmenopausal osteoporosis by increasing $1,25(\mathrm{OH})_{2} \mathrm{D}$. However, oestrogen-induced rise in $1,25(\mathrm{OH})_{2} \mathrm{D}$ serum levels has been found to be due to an increase of serum DBP, resulting in unchanged free $1,25(\mathrm{OH})_{2} \mathrm{D}$ levels after treatment with estrogens (Bouillon et al., 1981; Dick et al., 1995). In a later study, Balhorn et al. (1997) did not find again a significant positive effect on intestinal calcium absorption by oestrogen treatment. However, it should be noted that this study (Balhorn et al., 1997) concerned normal elderly women whereas their first study concerned osteoporotic postmenopausal patients (Gallagher et al., 1980).

In our present study we found that oestrogen significantly increased serum levels of total $1,25(\mathrm{OH})_{2} \mathrm{D}$ and DBP but did not change the calculated free $1,25(\mathrm{OH})_{2} \mathrm{D}$ fraction, indicating that oestrogen treatment has an effect on vitamin D metabolism within two months of treatment. The data support previous studies which have found no effect of oral oestrogen on the free calcitriol level (Bouillon et al., 1981; Dick et al., 1995). Nevertheless, some previous studies have shown that oral oestrogen treatment results in increased levels of free calcitriol (Bikle et al., 1992; Cheema et al., 1989).

The lack of a change in intestinal strontium absorption is in agreement with the unchanged concentration of free serum $1,25(\mathrm{OH})_{2} \mathrm{D}$. However, it is generally held that the absorption efficiency for calcium is inversely related to the size of the ingested load (Heaney et al., 1989, 1990). At lower carrier loads principally active calcium absorption is measured. At high carrier loads, passive as well as active absorption is measured (Prince, 1994). Therefore, the relatively high oral load used in this test, i.e. $5 \mathrm{mmol}$ strontium and $9 \mathrm{mmol}$ calcium (corresponding with $560 \mathrm{mg}$ calcium) may have reduced the sensitivity of the test. However, Balhorn et al. (1997) also failed to demonstrate a significant positive effect of long-term oestrogen treatment on intestinal calcium absorption in normal elderly women using ${ }^{45} \mathrm{Ca}$ with a calcium load of $100 \mathrm{mg}$.

The contradictory results regarding the effect of oestrogen on intestinal calcium absorption could not be explained by differences in the absorption tests used, i.e. single tracer- or dual tracer absorption tests. Although the most accurate method for assessment of intestinal calcium absorption is the dual tracer procedure, single tracer tests seem to have good options as a calcium absorption test for clinical application when comparing different subjects. Nevertheless, when examining the effect of interventions, for instance oestrogen, on intestinal calcium absorption within an individual subject, (single point) single tracer tests may have some drawbacks. First of all, measuring intestinal absorption using a single point single tracer absorption test can result in an imaginary change in intestinal absorption because of the possibility that oestrogen suppletion may alter the absorption profile of calcium/strontium. Secondly, possible changes in the rate of elimination (kidney, bone, intestine) of calcium can also change the plasma tracer concentration, which might result in an under- or overestimation of intestinal absorption. Therefore, the findings with a single tracer test have to be confirmed by limited numbers of patients in which the true bioavailability of calcium/strontium is exclusively measured at the basal level and after intervention.

A possible effect of oestrogen on gastric emptying could also not explain the conflicting results of the effect of oestrogen on intestinal calcium absorption since oestrogen does not significantly change gastric emptying in postmenopausal women with or without hormone replacement therapy (Hutson et al., 1989).

In conclusion, the present study demonstrated that 2 months of oestrogen therapy does not change intestinal calcium 
absorption. Total $1,25(\mathrm{OH})_{2} \mathrm{D}$ and vitamin D-binding protein increased, but the free $1,25(\mathrm{OH})_{2} \mathrm{D}$ fraction remained unchanged.

\section{Acknowledgement}

We are grateful to Ans Nicolaas, Edo Westerveen, Bas Joenje and Jelle Tinholt for their assistance in organising and performing this study. We wish to thank Prof. Dr. R. Bouillon for providing measurements of vitamin D-binding protein, the Laboratory of Clinical Chemistry and the Laboratory of Endocrinology, University Hospital Vrije Universiteit, Amsterdam, for the measurement of the biochemical parameters.

\section{References}

Arjmandi, B.H., Salih, M.A., Herbert, D.C., Sims, S.H. \& Kalu, D.N. (1993) Evidence for estrogen receptor-linked calcium transport in the intestine. Bone and Mineral, 21, 63-74.

Arjmandi, B.H., Hollis, B.W. \& Kalu, D.N. (1994) In vivo effect of $17 \beta-$ estradiol on intestinal calcium absorption in rats. Bone and Mineral, 26, 181-189.

Balhorn, K.E., Gallagher, J.C., Fowler, S.E. \& Kinyamu, H.K. (1997) 1,25-dihydroxyvitamin $\mathrm{D}_{3}$ (rocaltrol) increases calcium absorption and urine calcium excretion in the elderly. Journal of Bone and Mineral Research, 12, S356.

Barger-Lux, M.J. \& Heaney, R.P. (1995) Determinants of calcium absorption. Challenges of Modern Medicine, 7, 243-251.

Barto, R., Sips, A.J.A.M., van der Vijgh, W.J.F. \& Netelenbos, J.C. (1995) Sensitive method for analysis of strontium in human and animal plasma by graphite furnace atomic absorption spectrophotometry. Clinical Chemistry, 41, 1159-1163.

Bikle, D.D., Halloran, B.P., Harris, S.T. \& Portale, A.A. (1992) Progestin antagonism of estrogen stimulated 1,25-dihydroxyvitamin D levels. Journal of Clinical Endocrinology and Metabolism, 72, 519-523.

Blanchard, J. \& Aeschlimann, J.M. (1989) Calcium absorption in man: some dosing recommendations. Journal of Pharmacokinetics and Biopharmaceutics, 17, 631-644.

Bouillon, R., Van Baelen, H. \& De Moor, P. (1977) The measurement of the vitamin D-binding protein in human serum. Journal of Clinical Endocrinology and Metabolism, 45, 225-230.

Bouillon, R., Van Assche, F.A. \& Van Baelen, H. (1981) Influence of the vitamin-D-binding protein on the serum concentration of 1,25 dihydroxyvitamin $\mathrm{D}_{3}$. Journal of Clinical Investigation, 67, 589596.

Cheema, C., Grant, B.F. \& Marcus, R. (1989) Effects of estrogen on circulating 'free' and total 1,25-dihydroxyvitamin $\mathrm{D}$ and on the parathyroid-vitamin D axis in postmenopausal women. The Journal of Clinical Investigation, 83, 537-542.

Civitelli, R., Agnusdei, D., Nardi, P., Zacchei, F., Avioli, L.V. \& Gennari, C. (1988) Effects of one year treatment with estrogens on bone mass, intestinal calcium absorption and 25-hydroxyvitamin D$1 \alpha$-hydroxylase reserve in postmenopausal osteoporosis. Calcified Tissue International, 42, 77-86.

Dick, I.M., Prince, R.L., Kelly, J.J. \& Ho, K.K.Y. (1995) Oestrogen effects on calcitriol levels in post-menopausal women: a comparison of oral versus transdermal administration. Clinical Endocrinology, 43, 219-224.
Francis, R.M., Peacock, M., Taylor, G.A., Storer, J.H. \& Nordin, B.E.C. (1984) Calcium malabsorption in elderly women with vertebral fractures: evidence for resistance to the action of vitamin D metabolites in the bowel. Clinical Science, 66, 103-107.

Gallagher, J.C., Riggs, B.L., Eisman, J., Hamstra, A., Arnaud, S.B. \& DeLuca, H.F. (1979) Intestinal calcium absorption and serum vitamin D metabolites in normal subjects and osteoporotic patients. Journal of Clinical Investigation, 64, 719-736.

Gallagher, J.C., Riggs, B.L. \& DeLuca, H.F. (1980) Effect of estrogen on calcium absorption and serum vitamin D metabolites in postmenopausal osteoporosis. Journal of Clinical Endocrinology and Metabolism, 51, 1359-1364.

Gallagher, J.C. (1990) The pathogenesis of osteoporosis. Bone and Mineral, 9, 215-227.

Gennari, C., Agnusdei, D., Nadi, P. \& Civitelli, R. (1990) Estrogen preserves a normal intestinal responsiveness to 1,25-dihydroxyvitamin $\mathrm{D}_{3}$ in oophorectomized women. Journal of Clinical Endocrinology and Metabolism, 71, 1288-1293.

Gennari, L., Becherini, L., Masi, L., Gonnelli, S., Cepollaro, C., Martini, S., Mansani, R. \& Brandi, M.L. (1997) Vitamin D receptor genotypes and intestinal calcium absorption in postmenopausal women. Calcified Tissue International, 61, 460-463.

Heaney, R.P., Recker, R.R. \& Saville, P.D. (1978) Menopausal changes in calcium balance performance. Journal of Laboratory and Clinical Medicine, 92, 953-963.

Heaney, R.P., Recker, R.R., Stegman, M.R. \& Moy, A.J. (1989) Calcium absorption in women: relationships to calcium intake, estrogen status and age. Journal of Bone and Mineral Research, 4, 469-475.

Heaney, R.P., Weaver, C.M. \& Fitzsimmons, M.L. (1990) Influence of calcium load on absorbed fraction. Journal of Bone and Mineral Research, 5, 1135-1138.

Hutson, W.R., Roehrkasse, R.L. \& Wald, A. (1989) Influence of gender and menopause on gastric emptying and motility. Gastroenterology, 96, $11-17$.

Miller, M.E., Cosgriff, J.M. \& Forbes, G.B. (1989) Bromide space determination using anion-exchange chromatography for measurement of bromide. American Journal of Clinical Nutrition, 50, 168171.

Morris, H.A., Need, A.G., Horowitz, M., O’Loughlin, P.D. \& Nordin, B.E.C. (1991) Calcium absorption in normal and osteoporotic postmenopausal women. Calcified Tissue International, 49, 240243.

Need, A.G., Horowitz, M., Philcox, J.C. \& Nordin, B. (1987) Biochemical effects of a calcium supplement in osteoporotic postmenopausal women with normal absorption and malabsorption of calcium. Mineral and Electrolyte Metabolism, 13, 112-116.

Prince, R.L. (1994) COUNTERPOINT: Estrogen effects on calcitropic hormones and calcium homeostasis. Endocrine Reviews, 15, 301309.

Reid, I.R., Pybus, J., Lim, T.M.T., Hannon, S. \& Ibbertson, H.K. (1986) The assessment of intestinal calcium absorption using stable strontium. Calcified Tissue International, 8, 303-305.

Selby, P.L., Peacock, M., Barkworth, S.A., Brown, W.B. \& Taylor, G.A. (1985) Early effects of ethinyloestradiol and norethisterone treatment in post-menopausal women on bone resorption and calcium regulating hormones. Clinical Science, 69, 265-271.

Sips, A.J.A.M., van der Vijgh, W.J.F., Barto, R. \& Netelenbos, J.C. (1996) Intestinal absorption of strontium chloride in healthy volunteers: pharmacokinetics and reproducibility. British Journal of Clinical Pharmacology, 41, 543-549.

(C) 1999 Blackwell Science Ltd, Clinical Endocrinology, 50, 387-392 